\title{
PRODUTIVIDADE E DESENVOLVIMENTO DA CANA- PLANTA E SOCA EM FUNÇÃO DE DOSES E FONTES DE MANGANÊS ${ }^{(1)}$
}

\author{
Cleiton Gredson Sabin Benett ${ }^{(2)}$, Salatiér Buzetti ${ }^{(3)}$, Katiane \\ Santiago Silva ${ }^{(2)}$, Marcelo Carvalho Minhoto Teixeira Filho ${ }^{(3)}$, \\ Cássia Maria de Paula Garcia ${ }^{(4)}$ \& Paulo Ricardo Maestrelo ${ }^{(5)}$
}

\begin{abstract}
RESUMO
A cana-de-açúcar possui grande importância econômico-social e política para o Brasil. Este trabalho teve como objetivo avaliar o efeito de doses e fontes de manganês nessa cultura. O experimento foi realizado no sítio Fujimoto, área administrada pela Destilaria Vale do Paraná S/A Álcool e Açúcar, no município de Suzanápolis, SP. O delineamento experimental utilizado foi o de blocos ao acaso no esquema fatorial $5 \times 3$, sendo cinco doses de $\operatorname{Mn}\left(0 ; 2,5 ; 5,0 ; 7,5 ;\right.$ e $\left.10,0 \mathrm{~kg} \mathrm{ha}^{-1}\right)$ e três fontes (quelato, FTE e sulfato de manganês), aplicadas no sulco de plantio, em quatro repetições. As parcelas foram constituídas por quatro linhas de $5 \mathbf{m}$ de comprimento e espaçadas $1,5 \mathrm{~m}$. A variedade de cana-de-açúcar utilizada foi a RB 86-7515, realizando-se dois cortes. As fontes de Mn proporcionaram semelhantes produtividades de colmos, tanto da cana-planta quanto da primeira cana-soca. $\mathrm{O}$ quelato de Mn proporcionou maior número de colmo por metro de sulco na canasoca. As doses de Mn não influenciaram a produtividade de colmos da cana-planta e da cana- soca, porém aumentaram o número de internódios e o diâmetro de colmo na cana-planta até as doses de 6,9 e $6,6 \mathrm{~kg} \mathrm{ha}^{-1}$ de $\mathrm{Mn}$, respectivamente.
\end{abstract}

Termos de indexação: Saccharum spp., adubação, micronutriente, perfilhos.

\footnotetext{
(1) Parte da tese de doutorado do primeiro autor. Recebido para publicação em 20 de janeiro de 2011 e aprovado em 6 de junho de 2011.

(2) Profs. Drs. da Universidade Estadual de Mato Grosso do Sul - UEMS/UUA, Unidade Universitária de Aquidauana-MS. Emails: cbenett@hotmail.com; kasantiago@ig.com.br

(3) Profs. Drs. da Universidade Estadual Paulista, UNESP/FE, Campus de Ilha Solteira-SP. E-mails: sbuzetti@agr.feis.unesp.br; mcmtf@yahoo.com.br

(4) Mestranda em agronomia (sistema de produção), UNESP/FE - Campus de Ilha Solteira-SP. E-mail: cassiampg@yahoo.com.br

(5) Graduandos em agronomia, UNESP/FE - Campus de Ilha Solteira-SP. E-mail: paulomaestrelo@hotmail.com
} 


\title{
SUMMARY: YIELD AND DEVELOPMENT OF PLANT CANE AND RATOON CANE AS RELATED TO MANGANESE RATES AND SOURCES
}

\begin{abstract}
Sugar cane plays an important economic-social and political role in Brazil. This study aimed to evaluate the effect of manganese doses and sources on sugar cane. The experiment was conducted on the Sitio Fujimoto, an area administered by the Distillery Vale do Paraná S / A Alcohol and Sugar in Suzanápolis, São Paulo state. The experiment was arranged in a randomized block, $5 \times 3$ factorial design, with 5 manganese rates $\left(0,2.5,5.0,7.5\right.$ and $\left.10.0 \mathrm{~kg} \mathrm{ha}^{-1}\right)$ and 3 sources (chelate, FTE and manganese sulfate), applied in the furrow, with four replications. The plots consisted of four $5 \mathrm{~m}$ long rows, spaced $1.5 \mathrm{~m}$ apart. The sugar cane variety $R B$ 867515 was evaluated in two harvests. The Mn sources produced similar stalk yields, for plant cane as well as first ratoon cane. The Mn chelate resulted in more stalks per row meter in sugarcane ratoon. The Mn rates did not affect the stalk yield of plant cane and ratoon, but increased the number of internodes and stem diameter in plant cane up to 6.9 and $6.6 \mathrm{~kg} \mathrm{ha-1}$ $M$, respectively.
\end{abstract}

Index terms: Saccharum spp., fertilization, micronutrients, tillers.

\section{INTRODUÇÃO}

A cana-de-açúcar (Saccharum spp.) atualmente é uma das culturas mais importantes no cenário socioeconômico brasileiro, por ser a principal matériaprima utilizada pela indústria sucroalcooleira para a produção de açúcar e álcool.

O Brasil destaca-se como o maior produtor mundial de cana-de-açúcar, com produção na safra de 2009/2010 de aproximadamente $600 \mathrm{Mt}$ em 7,4 M ha. O Estado de São Paulo é maior produtor nacional, com 4,1 M ha plantados, cuja produção é destinada à fabricação de açúcar e etanol, revelando-se a maior agroindústria do país e responsável por 362,6 Mt de colmos (CNAB, 2011).

As agriculturas mundial e brasileira atravessam uma fase em que a produtividade, a eficiência, a lucratividade e a sustentabilidade dos processos produtivos são aspectos da maior relevância. Com a evolução dos tempos, ficou comprovada na agricultura que a adubação é um dos fatores que determinam a produtividade. Porém, a utilização de micronutrientes em cana-de-açúcar ainda apresenta controvérsia em relação ao seu efeito na produtividade (Vazquez \& Sanches, 2010).

O emprego de micronutrientes em cana-de-açúcar está relacionado à essencialidade desses elementos para as plantas e suas funções no metabolismo delas, aos sintomas visuais de deficiência observados a campo em plantas com suprimento inadequado desses elementos, segundo a técnica da diagnose foliar, em comparação com teores de plantas sadias e de canaviais com altas produtividades; aos baixos teores no solo, principalmente nos arenosos, com baixo teor de matéria orgânica e sem a utilização de resíduos da própria indústria canavieira ou de outras fontes orgânicas; e as novas variedades mais produtivas e mais exigentes em micronutrientes (Vazquez \& Silva, 2008).

A carência de micronutrientes leva a reduções na produtividade e até a morte de plantas, já que estas são consequências naturais advindas de desarranjos nos processos metabólicos e as quantidades necessárias são relativamente baixas quando comparadas com a extração de macronutrientes, porém desempenham fundamental importância no desenvolvimento da cultura (Orlando Filho, 1993). Já o excesso ou teores altos de micronutrientes no solo podem causar toxidez às plantas.

O Mn atua na fotossíntese, sendo envolvido na estrutura, funcionamento e multiplicação de cloroplastos, além de realizar o transporte eletrônico (Vitti et al., 2006) e ser requerido para a atividade de algumas desidrogenases, descarboxilases, quinases, oxidases e peroxidases. Está envolvido com outras enzimas ativadas por cátions e na evolução fotossintética de oxigênio (Taiz \& Zeiger, 2004).

No solo, o Mn pode ser encontrado em três formas principais: trocável, complexado organicamente e associado a óxidos. Da interação entre essas três formas resulta sua disponibilidade para as plantas. Essa interação depende do tipo de solo, $\mathrm{pH}$ e teor de matéria orgânica (Marschner, 1995).

O Mn é, assim, o segundo micronutriente mais extraído do solo pela cultura da cana-de-açúcar, e a sua falta pode ocasionar problemas à cultura canavieira, principalmente baixa produtividade. Conforme Chaves e Farias (2009), isso resulta em caldo com maior teor de fenóis e amido, compostos que durante o processamento da cana ou estocagem do açúcar se oxidam, alterando a cor do alimento ou da bebida.

Nesse contexto e considerando que a região Noroeste do Estado de São Paulo passou a ser fronteira 
produtora de cana-de-açúcar em substituição às pastagens, este trabalho teve como objetivo avaliar o efeito de cinco doses de Mn aplicadas no sulco de plantio, usando-se de três fontes (quelato, FTE e sulfato de manganês) na cultura da cana, em dois cortes.

\section{MATERIAL E MÉTODOS}

O experimento foi realizado no município de Suzanápolis, situado no Noroeste do Estado de São Paulo, com coordenadas $20^{\circ} 30^{\prime} 3$ " S e 51 ${ }^{\circ} 1^{\prime} 30$ " $\mathrm{O}$ e altitude de $350 \mathrm{~m}$. O solo da área experimental foi classificado como Argissolo Vermelho eutrófico
(Embrapa, 2006). As propriedades químicas do solo foram determinadas antes da instalação do experimento, segundo métodos propostos por Raij et al. (2001), cujos resultados da análise química estão apresentados no quadro 1. A análise granulométrica na camada de 0 a $25 \mathrm{~cm}$ exibiu valores de 820,56 e $124 \mathrm{~g} \mathrm{~kg}^{-1}$ de areia, silte e argila, respectivamente. $\mathrm{O}$ clima da região é classificado como Aw pela classificação de Köppen, com temperatura média anual de $23,7^{\circ} \mathrm{C}$ e precipitação pluvial média anual de $1.300 \mathrm{~mm}$. Os dados climáticos referentes ao período experimental encontram-se na figura 1 .

O delineamento experimental utilizado foi o de blocos ao acaso, no esquema fatorial 5 x 3 , sendo cinco doses de manganês $\left(0 ; 2,5 ; 5,0 ; 7,5 ;\right.$ e $\left.10,0 \mathrm{~kg} \mathrm{ha}^{-1}\right) \mathrm{e}$

Quadro 1. Análise química do solo na área experimental. Suzanápolis-SP, 2007

\begin{tabular}{|c|c|c|c|c|c|c|c|c|c|c|c|c|c|c|c|}
\hline Camada & $P$ resina & MO & pH CaCl $\mathrm{CaC}_{2}$ & $\mathbf{K}^{+}$ & $\mathrm{Ca}^{2+}$ & $\mathrm{Mg}^{2+}$ & $\mathbf{H}+\mathbf{A l}$ & SB & CTC & $\mathbf{V}$ & $\mathrm{Cu}^{(1)}$ & $F e^{(1)}$ & $\mathbf{M n}^{(1)}$ & $\mathbf{Z n}^{(1)}$ & $\mathbf{B}^{(2)}$ \\
\hline $\mathrm{cm}$ & $\mathrm{mg} \mathrm{dm} \mathrm{m}^{-3}$ & $\mathrm{~g} \mathrm{dm}^{-3}$ & & & 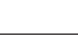 & - $\mathrm{mm}$ & $\mathrm{ol}_{\mathrm{c}} \mathrm{dm}^{-3}$ & & & $\%$ & 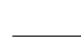 & & $\mathrm{mg} \mathrm{dm}{ }^{-3}$ & & \\
\hline $0-25$ & 3 & 24 & 4,9 & 3,0 & 10 & 8 & 20 & 21,4 & 41,4 & 52 & 0,8 & 13 & 4,8 & 0,4 & 0,61 \\
\hline $25-50$ & 2 & 12 & 4,6 & 0,3 & 9 & 4 & 21 & 13,3 & 34,3 & 39 & 0,9 & 8 & 2,5 & 0,1 & 0,50 \\
\hline
\end{tabular}

(1) Determinado em DTPA. ${ }^{(2)}$ Água quente. Análise química realizada no Laboratório de Fertilidade do Solo da UNESP/FE.

(a)

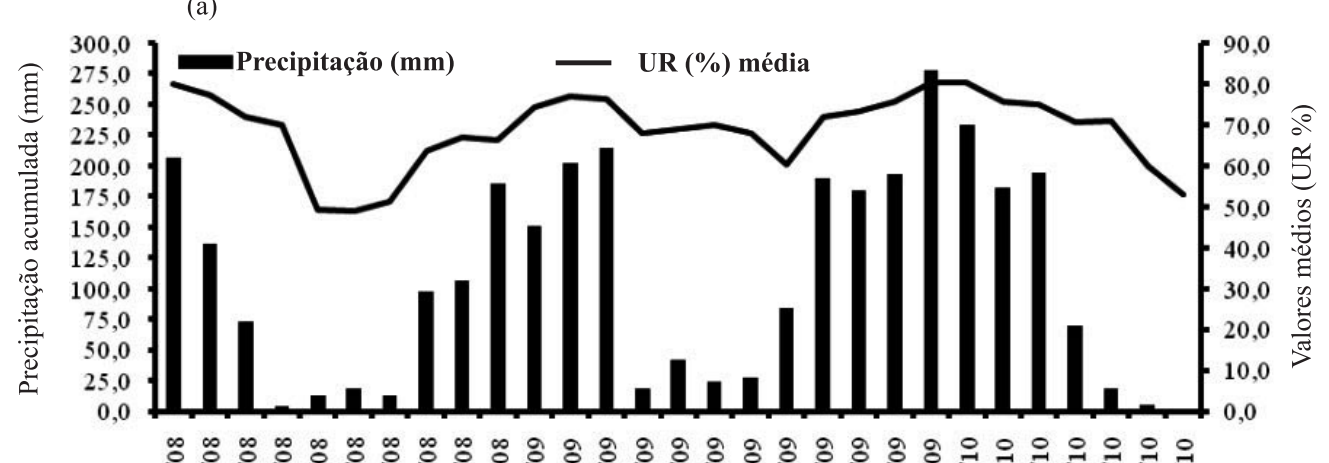

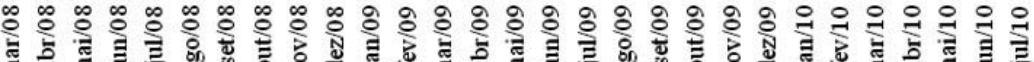

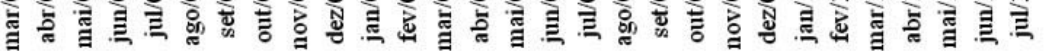

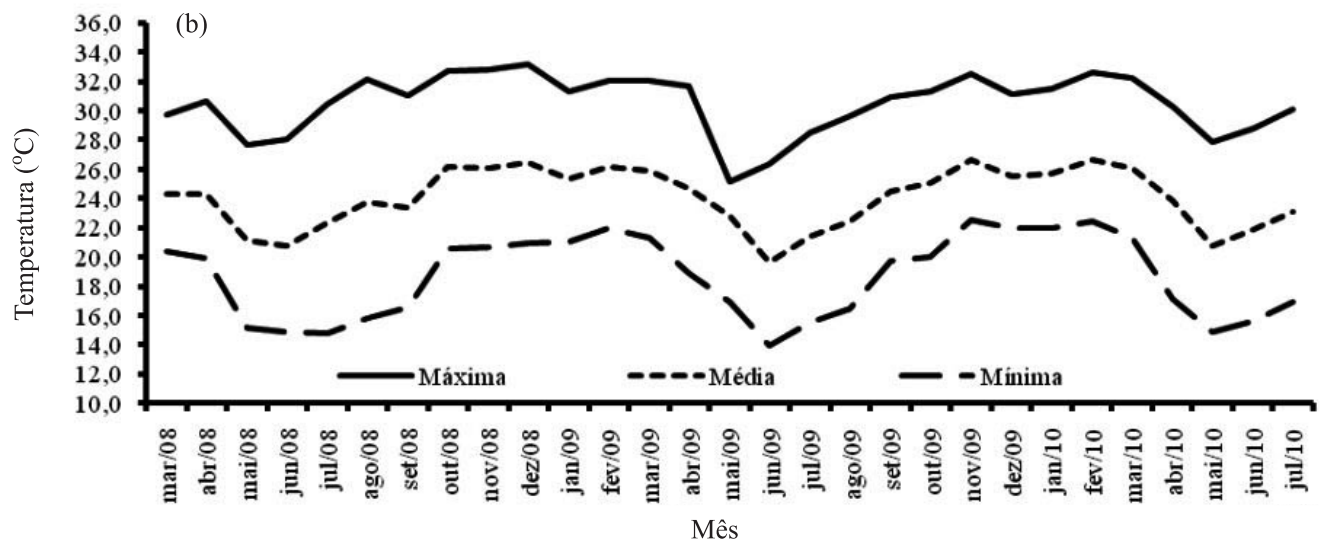

Figura 1. Valores de precipitação acumulada durante o mês, umidade relativa (a) e temperaturas máxima, média e mínima (b) no período experimental, na cultura da cana-planta e cana-soca. Suzanápolis-SP, 2008 a 2010. * Valores extraídos das estações agrometeorológicas da UNESP/FE de Ilha Solteira-SP e Marinópolis-SP. 
três fontes: Quelato (7\% Mn), FTE BR 12 pó (1,8 \% B; 0,8 \% Cu; 3,0 \% Fe; 2,0 \% Mn; 0,10\% Mo; e 9,0\% $\mathrm{Zn})$ e sulfato de manganês (31\% Mn e $18 \% \mathrm{~S})$, aplicadas no sulco de plantio, em quatro repetições. O FTE foi utilizado para verificar o seu efeito residual, já que é produto de baixa solubilidade, e analisar a sua capacidade de fornecimento de nutrientes à canade-açúcar, uma vez que, além de $\mathrm{Mn}$, foram analisados o $\mathrm{B}, \mathrm{Cu}, \mathrm{Fe}$ e $\mathrm{Zn}$, constatado em outro trabalho. Como o solo estava deficiente em Zn, aplicaram-se em todos os tratamentos $5 \mathrm{~kg} \mathrm{ha}^{-1}$ do elemento (sulfato de zinco). Os tratamentos fonte e doses foram aplicados apenas no sulco de plantio, imediatamente antes do plantio da cana-planta. As parcelas foram constituídas por quatro linhas de $5 \mathrm{~m}$ de comprimento e espaçadas $1,5 \mathrm{~m}$. No preparo do solo foram realizadas uma aração e uma aplicação de $2 \mathrm{t} \mathrm{ha} \mathrm{a}^{-1}$ de calcário, fazendose posteriormente duas gradagens.

A cultura recebeu adubação de macronutrientes com 30,150 e $120 \mathrm{~kg} \mathrm{ha}^{-1}$ de $\mathrm{N}, \mathrm{P}_{2} \mathrm{O}_{5}$ e $\mathrm{K}_{2} \mathrm{O}$, respectivamente, conforme descrito por Raij et al. (1997). Na cana-soca (primeira soca) foi realizada a aplicação de macronutrientes com 80 e $60 \mathrm{~kg} \mathrm{ha}^{-1} \mathrm{de}$ $\mathrm{N}$ e $\mathrm{K}_{2} \mathrm{O}$, respectivamente, de acordo com as recomendações de Raij et al. (1997), aplicados nas entrelinhas da cultura no dia 16 de outubro de 2009. Foram usados como fontes ureia, superfosfato simples e cloreto de potássio.

A variedade da cana-de-açúcar utilizada foi a RB 867515, cujo plantio foi realizado em 17 de março de 2008, adotando-se o sistema de plantio manual (convencional), em que os toletes foram distribuídos dentro dos sulcos de plantio, sendo colocados seis toletes com três gemas $\mathrm{m}^{-1}$ de sulco. As colheitas foram realizadas sem queima e manualmente, sendo a canaplanta colhida no dia 8 de julho de 2009 e a primeira soca, em 5 de julho de 2010.

As variáveis analisadas na cana-planta e na canasoca se deram em cada parcela, obtendo-se a média aritmética do número de perfilho por metro, o qual foi realizado contando-se a quantidade de colmos em $5 \mathrm{~m}$ de sulco. O índice de clorofila foliar (ICF) foi mensurado na posição do terço médio da lâmina foliar da folha +3 expandida a partir do ápice de cada planta, por meio de clorofilômetro digital Falker, realizando em três plantas por parcela no período de 64,131 , $208,275,327,388$ e 476 dias após o plantio em canaplanta e aos 80, 150, 212, 262 e 345 dias após o corte em cana-soca. A altura média de colmos foi avaliada em três plantas por parcela, com o auxílio de régua graduada do nível do solo até a primeira aurícula visível, classificada como folha +1 , enquanto para conhecer o diâmetro de colmo foi utilizado um paquímetro, medindo-se o diâmetro na base, meio e ponta de três colmos por parcela. O número de internódios foi determinado contando-se o número de internódios presentes em $3 \mathrm{~m}$ de colmo. A produção de colmos por hectare foi determinada contando-se o número de colmos da área útil da parcela, cortando- se 10 colmos industrializáveis por parcela, pesandoos e calculando a produtividade em tha ${ }^{-1}$ de cana.

Os dados foram submetidos à análise de variância (teste F) e as médias, comparadas pelo teste de Tukey a $5 \%$ para fontes, sendo realizadas as análises de regressão das doses de $\mathrm{Mn}$.

\section{RESULTADOS E DISCUSSÃO}

Os valores referentes ao número médio de perfilho por metro e índice de clorofila foliar (ICF) da canaplanta encontram-se no quadro 2 . As fontes e doses de manganês não apresentaram efeito significativo sobre o número médio de colmos e o índice ICF da cana-planta durante o período avaliado. Já na época de avaliação foi observado efeito significativo de número de colmos por metro de sulco e índice ICF (Quadro 2).

O maior perfilhamento ocorreu aos 131 DAP (dias após o plantio) e, o menor, aos $476 \mathrm{DAP}$, havendo redução de aproximadamente $68 \%$ do maior perfilhamento até a colheita. O perfilhamento tem influência direta na produção da cana-de-açúcar e cada cultivar, um potencial de perfilhamento. Este é um dos componentes para a formação do potencial agrícola, em conjunto com a altura e diâmetro de colmos (Landell; Silva, 2004). A redução no número de perfilho por metro é característica fisiológica da cultura

Quadro 2. Número de perfilhos por metro de sulco e índice ICF em função de fontes, épocas de avaliação e doses de manganês na cultura da cana-de-açúcar (cana-planta). Suzanápolis-SP, 2009

\begin{tabular}{|c|c|c|}
\hline \multirow{2}{*}{ Tratamento } & \multicolumn{2}{|c|}{ Cana planta } \\
\hline & Perfilho $\mathrm{m}^{-1}$ & Clorofila (ICF) \\
\hline \multicolumn{3}{|l|}{ Fontes } \\
\hline Quelato & $10,9 \mathrm{a}$ & $38,6 \mathrm{a}$ \\
\hline FTE BR 12 & $10,8 \mathrm{a}$ & $38,3 \mathrm{a}$ \\
\hline Sulfato de Manganês & $10,8 \mathrm{a}$ & 39,0 a \\
\hline \multicolumn{3}{|l|}{ Avaliações (DAP) $)^{(1)}$} \\
\hline 64 & $10,4 \mathrm{c}$ & $43,9 \mathrm{~b}$ \\
\hline 131 & $14,1 \mathrm{a}$ & $37,7 \mathrm{~d}$ \\
\hline 208 & $11,8 \mathrm{~b}$ & $32,2 \mathrm{e}$ \\
\hline 275 & $10,5 \mathrm{c}$ & $38,0 \mathrm{~d}$ \\
\hline 327 & $10,2 \mathrm{c}$ & $46,6 \mathrm{a}$ \\
\hline 388 & $10,3 \mathrm{c}$ & $40,2 \mathrm{c}$ \\
\hline 476 & $8,4 \mathrm{~d}$ & $32,0 \mathrm{e}$ \\
\hline \multicolumn{3}{|l|}{ Dose de $\operatorname{Mn}\left(\mathrm{kg} \mathrm{ha}^{-1}\right)$} \\
\hline 0 & 10,7 & 38,5 \\
\hline 2,5 & 11,0 & 38,6 \\
\hline 5,0 & 10,9 & 38,6 \\
\hline 7,5 & 10,6 & 38,7 \\
\hline 10,0 & 10,8 & 38,8 \\
\hline $\mathrm{CV}(\%)$ & 15,93 & 8,91 \\
\hline
\end{tabular}

(1) DAP: Dias Após o Plantio. Médias seguidas pela mesma letra na coluna não diferem entre si, pelo teste de Tukey a $5 \%$. 
da cana-de-açúcar, que foi observada por diversos autores, como Dillewijn (1952), Castro e Christofoletti (2005) e Silva et al. (2007).

Oliveira et al. (2004) e Oliveira et al. (2005), trabalhando com diferentes cultivares RB85-5113, RB72454 e RB85-5536, constataram maior perfilhamento entre 135 e 182 DAP, com 7,4 a 23,0 perfilhos por metro de sulco, respectivamente. Ressalta-se que o perfilhamento depende das características genéticas de cada variedade (Oliveira et al., 2007).

Quanto aos valores médios das leituras em clorofilômetro (Quadro 2), houve efeito significativo de épocas de amostragem, em que o maior valor foi observado aos 327 DAP, com leitura ICF de 46,6. Nesse período houve maior incidência de chuvas, ocasionando melhor absorção de Mn pela planta. Portanto, tal resultado ocorreu porque o $\mathrm{Mn}$ atua no processo da fotossíntese, estando envolvido na estrutura, funcionamento e multiplicação de cloroplastos (Vitti et al., 2006). O'Neil et al. (2006) relataram que a diminuição das leituras do SPAD-502 depende, principalmente, das características genéticas da planta e condições climáticas.

No quadro 3, encontram-se os valores referentes ao número médio de colmos por metro e índice ICF da cana-soca. Quando foram avaliadas as fontes de Mn, verificou-se efeito significativo de colmos por metro, em que as fontes Quelato e FTE proporcionaram maior perfilhamento, diferindo do sulfato de manganês. Nas doses de Mn, não se observou efeito significativo (Quadro 3).

Quadro 3. Número de perfilhos por metro linear e índice ICF em função de fontes, épocas de avaliação e doses de manganês na cultura da cana-de-açúcar (cana-soca). Suzanápolis-SP, 2010

\begin{tabular}{ccc}
\hline \multirow{2}{*}{ Tratamento } & \multicolumn{2}{c}{ Cana soca } \\
\cline { 2 - 3 } & Perfilho m $^{-1}$ & Clorofila (ICF) \\
\hline Fontes & & \\
Quelato & $11,7 \mathrm{a}$ & $37,0 \mathrm{a}$ \\
FTE BR 12 & $11,3 \mathrm{ab}$ & $36,5 \mathrm{a}$ \\
Sulfato de Manganês & $11,2 \mathrm{~b}$ & $36,8 \mathrm{a}$ \\
Avaliações (DAC) ${ }^{(1)}$ & & \\
80 & $14,2 \mathrm{a}$ & $40,9 \mathrm{a}$ \\
150 & $13,0 \mathrm{~b}$ & $35,9 \mathrm{~b}$ \\
212 & $10,6 \mathrm{c}$ & $35,8 \mathrm{~b}$ \\
262 & $10,3 \mathrm{c}$ & $35,7 \mathrm{~b}$ \\
345 & $8,7 \mathrm{~d}$ & $35,6 \mathrm{~b}$ \\
Dose de Mn (kg ha $\left.{ }^{-1}\right)$ & & \\
0 & 11,3 & 37,3 \\
2,5 & 11,7 & 36,3 \\
5,0 & 11,6 & 38,3 \\
7,5 & 11,0 & 35,5 \\
10,0 & 11,4 & 36,4 \\
CV $(\%)$ & 13,40 & 6,60 \\
\hline
\end{tabular}

(1) DAC: Dias Após o Corte. Médias seguidas pela mesma letra na coluna não diferem entre si, pelo teste de Tukey a $5 \%$.
Ao avaliar as épocas, verificou-se efeito significativo aos $80 \mathrm{DAC}$ (dias após o corte), havendo o maior perfilhamento, e aos $345 \mathrm{DAC}$, o menor perfilhamento (Quadro 3). Almeida et al. (2008) verificaram perfilhamento semelhante na cultivar RB 92-579 aos 90 dias após o corte. Silva et al. (2008), trabalhando com as cultivares RB 72-2454 e IAC 86-2480, encontraram máximo perfilhamento aos 90 dias, com cerca de 19 e 21 perfilhos por metro de sulco, respectivamente.

Silva et al. (2007) e Wiedenfeld (2003) citaram que o crescimento inicial rápido e uniforme conduz a cultura a um bom estande. Isso possibilita o rápido fechamento de entrelinhas e o controle mais efetivo das plantas daninhas, além da cobertura homogênea do solo, que promove eficiente aproveitamento da energia luminosa pela planta.

Os valores médios de leitura em clorofilômetro (Quadro 3) revelaram efeito significativo somente aos 80 DAC, com valor de 40,9, não diferindo nos demais períodos de avaliação. Teixeira et al. (2004) observaram que as leituras em clorofilômetro mostraram-se eficaz para estimar os teores de clorofila no feijoeiro submetido à adubação de manganês.

Os dados referentes à altura média de colmos e número de internódios da cana-planta e cana-soca estão apresentados no quadro 4.

Quando foram avaliadas as fontes de Mn, não se observou efeito significativo dessas avaliações em nenhum dos períodos testados. Gava et al. (2003) constataram que o crescimento máximo da cultura ocorreu durante o período inicial de crescimento, havendo acréscimo gradual até a fase de maturação. Barbosa (2005), trabalhando com cinco variedades em sistemas irrigado e de sequeiro, não observou efeito significativo na altura média de colmos no estádio de colheita.

Quadro 4. Altura média de colmos (AC) e número de internódios (NI) em função de fontes e doses de manganês na cultura da cana-de-açúcar. Suzanápolis-SP, 2009 e 2010

\begin{tabular}{|c|c|c|c|c|}
\hline \multirow{2}{*}{ Tratamento } & \multicolumn{2}{|c|}{ Cana planta } & \multicolumn{2}{|c|}{ Cana soca } \\
\hline & $\mathrm{AC}$ & NI & AC & NI \\
\hline Fontes & & & & \\
\hline Quelato & $2,89 \mathrm{a}$ & $9,28 \mathrm{a}$ & $2,91 \mathrm{a}$ & $8,43 \mathrm{a}$ \\
\hline FTE BR 12 & $2,87 \mathrm{a}$ & $8,98 \mathrm{a}$ & $2,92 \mathrm{a}$ & $8,63 \mathrm{a}$ \\
\hline $\begin{array}{l}\text { Sulfato de Manganês } \\
\text { Dose de } \operatorname{Mn}\left(\mathrm{kg} \mathrm{ha}^{-1}\right)\end{array}$ & $2,83 \mathrm{a}$ & 9,36 a & $2,94 \mathrm{a}$ & $8,76 \mathrm{a}$ \\
\hline 0 & 2,75 & 8,42 & 2,84 & 8,55 \\
\hline 2,5 & 2,90 & 9,69 & 2,91 & 8,77 \\
\hline 5,0 & 2,87 & 9,21 & 2,94 & 8,63 \\
\hline 7,5 & 2,91 & 9,24 & 2,97 & 8,39 \\
\hline 10,0 & 2,88 & 9,47 & 2,93 & 8,69 \\
\hline CV (\%) & 5,87 & 6,78 & 3,99 & 6,99 \\
\hline
\end{tabular}

Médias seguidas pela mesma letra na coluna não diferem entre si, pelo teste de Tukey a $5 \%$. 
Com relação às doses de $\mathrm{Mn}$ em cana-planta, observou-se efeito significativo no número de internódios, cujos valores se ajustaram à regressão quadrática com o ponto de máximo estimado em $6,9 \mathrm{~kg} \mathrm{ha}^{-1} \mathrm{de} \mathrm{Mn}$ (Figura 2). O aumento no número de internódios pode estar relacionado com a baixa precipitação pluvial e umidade relativa do ar durante a fase de crescimento dos colmos, ocorrendo entre os meses de julho a setembro. Shigaki (2003) e Gascho e Shih (1983) descreveram que a disponibilidade de água no solo pode ser o principal fator responsável pela maior elongação dos entrenós da cana-de-açúcar.

Quando foram avaliados o diâmetro médio do colmo e a produtividade de colmos da cana- planta e canasoca (Quadro 5), em função das fontes Mn, não foram constatados efeitos significativos em nenhuma das

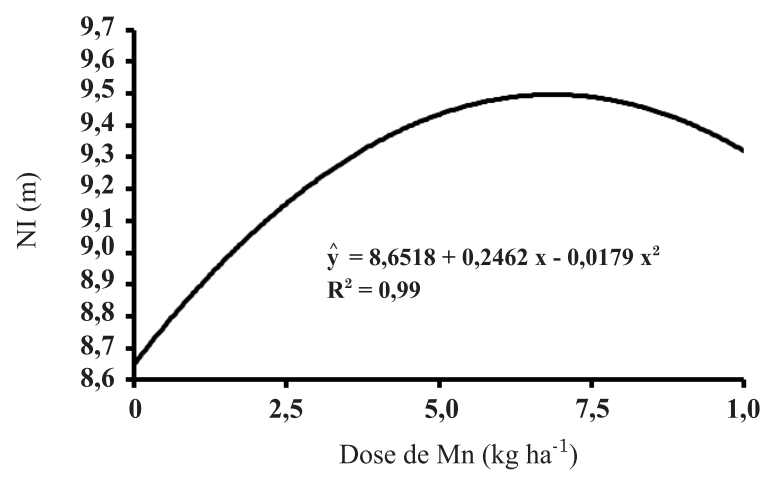

Figura 2. Número de internódios (NI) em função das doses de manganês na cultura da cana-de-açúcar (cana-planta). Suzanápolis-SP, 2009.

Quadro 5. Valores médios do diâmetro de colmo (DC) e tonelada de cana por hectare (TCH), em função de fontes e doses de manganês na cultura da cana-de-açúcar. Suzanápolis-SP, 2009 e 2010

\begin{tabular}{|c|c|c|c|c|}
\hline \multirow{2}{*}{ Tratamento } & \multicolumn{2}{|c|}{ Cana planta } & \multicolumn{2}{|c|}{ Cana soca } \\
\hline & DC & TCH & DC & TCH \\
\hline Fontes & $\mathrm{cm}$ & $\mathrm{tha}^{-1}$ & $\mathrm{~cm}$ & $\mathrm{tha}^{-1}$ \\
\hline Quelato & $2,59 \mathrm{a}$ & $93,5 \mathrm{a}$ & $2,70 \mathrm{a}$ & $99,7 \mathrm{a}$ \\
\hline FTE BR 12 & $2,57 \mathrm{a}$ & $93,3 \mathrm{a}$ & $2,68 \mathrm{a}$ & $101,6 \mathrm{a}$ \\
\hline Sulfato de Manganês & $2,63 \mathrm{a}$ & $88,7 \mathrm{a}$ & $2,69 \mathrm{a}$ & $97,3 \mathrm{a}$ \\
\hline \multicolumn{5}{|l|}{ Dose de $\mathrm{Mn}\left(\mathrm{kg} \mathrm{ha}^{-1}\right)$} \\
\hline 0 & 2,48 & 87,4 & 2,67 & 90,1 \\
\hline 2,5 & 2,65 & 91,1 & 2,64 & 101,0 \\
\hline 5,0 & 2,58 & 87,5 & 2,71 & 104,7 \\
\hline 7,5 & 2,66 & 93,8 & 2,69 & 99,8 \\
\hline 10,0 & 2,60 & 99,2 & 2,74 & 101,9 \\
\hline CV (\%) & 5,35 & 15,67 & 4,07 & 15,38 \\
\hline
\end{tabular}

Médias seguidas pela mesma letra na coluna não diferem entre si, pelo teste de Tukey a $5 \%$. variáveis. Já as doses de Mn afetaram significativamente o diâmetro do colmo da cana-planta (Figura 3).

Os valores do diâmetro médio do colmo se ajustaram à regressão quadrática com o ponto de máximo estimado em 6,6 $\mathrm{kg} \mathrm{ha}^{-1}$ de Mn (Figura 3). Paes et al. (1997), avaliando três cultivares de canade-açúcar, observaram que o diâmetro variou entre 2,6 e 3,0 cm, valores esses próximos aos obtidos neste trabalho. Ramesh e Mahadevas (2000), trabalhando com variedades de cana-de-açúcar, observaram efeito significativo no diâmetro do colmo aos 360 dias após o plantio. O diâmetro do colmo pode ser influenciado pela característica genética da própria planta e pelas condições climáticas, influenciando no diâmetro do colmo na fase de desenvolvimento da cultura.

A produtividade de colmos não se ajustou às regressões testadas, obtendo-se produtividades que variaram de 87 a $99 \mathrm{t} \mathrm{ha}^{-1}$ na cana-planta e de 90 a $104 \mathrm{t} \mathrm{ha}^{-1}$ na cana-soca (Quadro 5). A baixa produtividade da cana-planta pode ser explicada devido à menor precipitação durante o período de desenvolvimento da cultura. Gava et al. (2008) verificaram, em estudo com três variedades de canade-açúcar em primeiro ciclo de cultivo na região de Jaú, SP, produtividades de 115,8; 112,1; e 91,9 t ha-1 das variedades RB 86-7515, RB 85-5536 e SP 80-3280, respectivamente. Oliveira et al. (2008), estudando o comportamento de variedades de cana-de-açúcar em primeiro ciclo de cultivo na região de Carpina, $\mathrm{PE}$, obtiveram produtividades médias de $87,6 \mathrm{t} \mathrm{ha}^{-1}$ de RB 86-7515.

Nesse sentido, verificam-se poucos estudos enfocando o Mn na cultura da cana-de-açúcar e que a produtividade da cultura é dependente do solo, condições climáticas, variedade, manejo do solo, principalmente adubação, e manejo da própria cultura, em que a manutenção de um bom estande é fundamental.

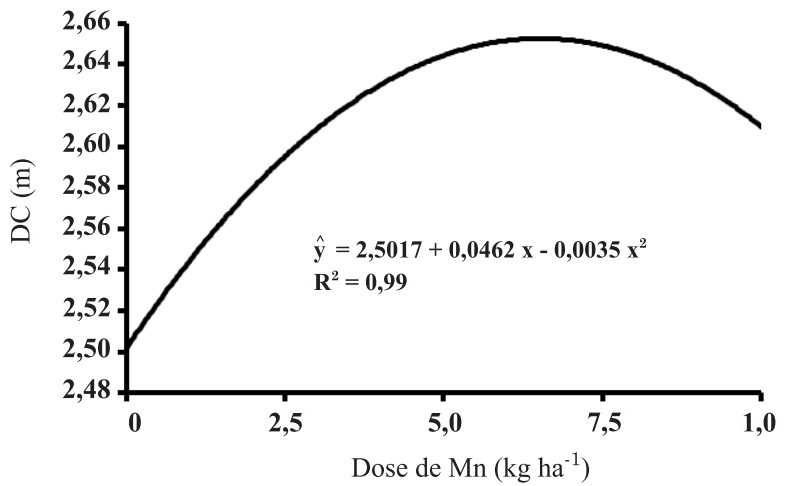

Figura 3. Diâmetro do colmo (DC) em função das doses de manganês na cultura da cana-de-açúcar (cana planta). Suzanápolis-SP, 2009. 


\section{CONCLUSÕES}

1. As fontes de Mn proporcionaram semelhantes produtividades de colmos, tanto para cana-planta quanto para primeira cana-soca.

2. O quelato de $\mathrm{Mn}$ proporcionou maior número de colmo por metro de sulco na cana- soca.

3. As doses de Mn não influenciaram na produtividade de colmos da cana-planta e da canasoca, porém aumentaram o número de internódios e o diâmetro de colmo na cana-planta até as doses de 6,9 e 6,6 $\mathrm{kg} \mathrm{ha}^{-1}$ de $\mathrm{Mn}$, respectivamente.

\section{AGRADECIMENTOS}

À Coordenação de Aperfeiçoamento de Pessoal de Nível Superior (CAPES), pela concessão de bolsa de estudo ao primeiro autor.

À Usina Vale do Paraná S/A Álcool e Açúcar, pelo apoio e fornecimento da área e equipamentos necessários à realização deste trabalho.

\section{LITERATURA CITADA}

ALMEIDA, A.C.S.; SOUZA, J.L.; TEODORO, I.; BARBOSA, G.V.S.; MOURA FILHO, G. \& FERREIRA JÚNIOR, R.A. Desenvolvimento vegetativo e produção de variedades de cana-de-açúcar em relação à disponibilidade hídrica e unidades térmicas. Ci. Agrotec., 32:1441-1448, 2008.

BARBOSA, E.A. Avaliação fitotécnica de cinco variedades de cana-de-açúcar para o município de Salinas - MG. Vitória da Conquista, Universidade Estadual do Sudoeste da Bahia, 2005. 70p. (Tese de Mestrado)

CASTRO, P.R.C. \& CHRISTOFFOLETI, P.J. Fisiologia da canade-açúcar. In: MENDONÇA, A.F. Cigarrinhas da canade-açúcar: Controle biológico. Maceió, Insecta, 2005. p.348 .

COMPANHIA NACIONAL DE ABASTECIMENTO - CONAB. Acompanhamento da Safra Brasileira: cana-de-açúcar. Terceiro levantamento. Brasília, 2011. Disponível em: < http://www.conab.gov.br/OlalaCMS/uploads/arquivos/ 11_01_06_09_14_50_boletim_cana_3o_lev_safra_2010_2011..pdfs. Acesso em: 07 jan. 2011.

CHAVES, L.H.G. \& FARIAS, C.H.A. Variabilidade espacial de cobre e manganês em Argissolo sob cultivo de cana-deaçúcar. R. Ci. Agron., 40:211-218, 2009.

DILLEWIJN, C.van. Botany of sugarcane. Walthan, Chronica Botanica, 1952. 371p.

EMPRESA BRASILEIRA DE PESQUISA AGROPECUÁRIA EMBRAPA. Centro Nacional de Pesquisa de Solos. Sistema brasileiro de classificação de solos. Rio de Janeiro, 2006. 306p.
GASCHO, G.J. \& SHIH, S.F. Sugarcane. In: TEARE, I.D. \& PEET, M.M., ed. Crop-water relations. New York, John Wiley, 1983. p.445-479.

GAVA, G.J.C.; SILVA, M.A.; CRUZ, J.C.S.; JERÔNIMO, E.M.; OLIVEIRA, M.W.; KRONTAL, Y.; VERED, E.; AGUIAR, F.L. \& PEDROSO, D.B. Produtividade e atributos tecnológicos de três cultivares de cana-de-açúcar irrigadas por gotejamento subsuperficial, In: CONGRESSO NACIONAL DA STAB, 2008, Maceió. Anais... Maceió, STAB, 2008. p.751-755.

GAVA, G.J.; TRIVELIN, P.C.O.; VITTI, A.C. \& OLIVEIRA, M.W. Recuperação do nitrogênio $\left({ }^{15} \mathrm{~N}\right)$ da uréia e da palhada por soqueira de cana-de-açúcar (Saccharum spp.). R. Bras. Ci. Solo, 4:621-630, 2003.

LANDELL, M.G.A. \& SILVA, M.A. As estratégias de seleção da cana em desenvolvimento no Brasil. Visão Agríc., 1:1823,2004 .

MARSCHNER, H. Mineral nutrition of higher plants. 2.ed. San Diego, Academic Press, 1995. 889p.

O'NEIL, P.M.; SHANAHAN, J.F. \& SCHEPERS, J.S. Use of chlorophyll fluorescence assessments to differentiate corn hybrid response to variable water conditions. Crop Sci., 46:681-687, 2006

OLIVEIRA, E.C.A.; OLIVEIRA, A.C.; OLIVVEIRA, R.I.; COSTA, S.A.; SIMÕES NETO, D.E. \& FREIRE, F.J. Rendimento de colmo e atributos tecnológicos de cultivares de canade-açúcar, plantadas no Nordeste, sob dois sistemas de irrigação, In: CONGRESSO NACIONAL DA STAB, 2008, Maceió. Anais... Maceió, STAB, 2008. p.756-761.

OLIVEIRA, R.A.; DAROS, E.; ZAMBON, J.L.C.; WEBER, H.; IDO, O.T.; BESPALHOK-FILHO, J.C.; ZUFFELLATORIBAS, K.C. \& SILVA, D.K.T. Área foliar em três cultivares de cana-de-açúcar e sua correlação com a produção de biomassa. Pesq. Agropec. Trop., 37:71-76, 2007.

OLIVEIRA, R.A.; DAROS, E.; ZAMBON, J.L.C.; WEBER, H.; IDO, O.T.; ZUFFELLATO-RIBAS, K.C.; KOEHLER, H.S. \& SILVA, D.K.T. Crescimento e desenvolvimento de três cultivares de cana-de-açúcar, em cana-planta, no estado do Paraná. Sci. Agr, 5:87-94, 2004.

OLIVEIRA, R.A.; DAROS, E.; ZAMBON, J.L.C.; WEBER, H.; IDO, O.T.; ZUFFELLATO-RIBAS, K.C.; KOEHLER, H.S. \& SILVA, D.K.T. Crescimento e desenvolvimento de três cultivares de cana-de-açúcar, em cana-planta, no estado do Paraná: Taxa de crescimento. Sci. Agr., 6:85-89, 2005.

ORLANDO FILHO, J. Calagem e adubação da cana-de-açúcar. In: CÂMARA, G.M.S. \& OLIVEIRA, E.A.M. Produção de cana-de-açúcar. Piracicaba, Fealq/USP, 1993. p.133-146.

PAES, J.M.U.; MARCIANO, N.; BRITO, C.H.; CARDOSO, A.A.; MARTINEZ, H.H.P. \& MENDES, A. Estudos de espaçamentos e doses de nitrogênio na produção e em algumas características biométricas de três variedades de cana-de-açúcar. STAB, 15:18-20, 1997.

RAIJ, B.van; CANTARELLA, H.; GUAGGIO, J.A. \& FURLANI, A.M.C. Recomendações de adubação e calagem para o Estado de São Paulo. 2.ed. Campinas, Instituto Agronômico de Campinas, 1997. 285p. (Boletim Técnico, 100) 
RAIJ, B.van; ANDRADE, J.C.; CANTARELLA, H. \& QUAGGIO, J.A. Análise química para avaliação da fertilidade de solos tropicais. Campinas, Instituto Agronômico de Campinas, 2001. 285p.

RAMESH, P. \& MAHADEVAS, W.M. Effect of formative phase drought on different classes os shoots, shoot mortality, cane attributes, yield and quality of four sugarcane cultivars. J. Agron. Crop Sci., 185:249-258, 2000.

SHIGAKI, F. Variedade de cana-de-açúcar para alimentação bovina cultivadas sob condições de déficit hídrico. Seropédica, Universidade Federal Rural do Rio de Janeiro, 2003. 70p. (Tese de Mestrado)

SILVA, M.A.; GAVA, G.J.C.; CAPUTO, M.M.; PINCELLI, R.P.; JERÔNIMO, E.M. \& CRUZ, J.C.S. Uso de reguladores de crescimento como potencializadores do perfilhamento e da produtividade em cana-soca. Bragantia, 66:545-552, 2007.

SILVA, M.A.; JERONIMO, E.M. \& DAL'COL LÚCIO, A. Perfilhamento e produtividade de cana-de-açúcar com diferentes alturas de corte e épocas de colheita. Pesq. Agropec. Bras., 43:979-986, 2008.

TAIZ, L. \& ZEIGER, E. Fisiologia vegetal. 3.ed. Tradução de SANTARÉM, E.R. Porto Alegre: Artmed, 2004. 719p.
TEIXEIRA, I.R.; BORÉM, A.; ANDRADE, M.J.B.; GIÚDICE, M.P. \& CECON, P.R. Teores de clorofila em plantas de feijoeiros influenciadas pela adubação com manganês e zinco. Acta Sci. Agron., 26:147-152, 2004.

VAZQUEZ, G.H. \& SANCHES, A.C. Formas de aplicação de micronutrientes na cultura da cana-de-açúcar. Nucleus, 7:267-276, 2010.

VAZQUEZ, G.H. \& SILVA, W.H.A. Uso de micronutrientes via tolete e via foliar na cultura da cana-de-açúcar. In: CONGRESSO INTERNACIONAL DE TECNOLOGIA NA CADEIA PRODUTIVA DA CANA-DE-AÇÚCARCONCANA, 2., Uberaba, 2008. Proceedings... Uberaba, 2008.

VITTI, G.C.; OLIVEIRA, D.B. \& QUINTINO, T.A. Micronutrientes na cultura da cana-de-açúcar. In: SEGATO, S.V.; PINTO, A.S.; JENDIROBA, E. \& NÓBREGA, J.C.M. Atualização em produção de canade-açúcar. Piracicaba, 2006. p.121-138.

WIEDENFELD, B. Enhanced sugarcane establishment using plant growth regulators. J. Am. Soc. Sugar Cane Technol., 23:48-61, 2003. 